\title{
Recurrent Childhood Visual Pathway Glioma
}

National Cancer Institute

\section{Source}

National Cancer Institute. Recurrent Childhood Visual Pathway Glioma. NCI Thesaurus.

Code C7529.

The reemergence of visual pathway glioma in childhood after a period of remission. 